\title{
Canine Model of Cardiorenal Failure
}

Hiromichi Suzuki ${ }^{1 *}$, Akira Matsumoto ${ }^{2}$, Marohito Murakami ${ }^{3}$, Mareo Naitoh ${ }^{4}$ and Takao Saruta ${ }^{5}$

${ }^{1}$ Department of Nephrology, Saitama Medical University, Japan

${ }^{2}$ Matsumoto Clinic, Japan

${ }^{3}$ Hino Municipal Hospital, Japan

${ }^{4}$ Sanokousei General Hospital, Sapporo Kosei General Hospital, Japan

${ }^{5}$ Emeritus Keio University, Japan

\begin{abstract}
The heart and the kidneys act in tandem to regulate blood pressure, vascular tone, diueresis and to maintain intravascular volume homeostasis. Besides, the kidneys have a neuroendocrine function with interdependent physiological actions regulated by the renin-angiotensin-aldosterone system, sympathetic nervous system, and vasopressin and aterial natriuretic peptide. To investigate these complex pathophysiological mechanisms, a canine model for Congestive Heart Failure (CHF) compromised with Renal Dysfunction (RF) was used, to characterize the hemodynamic and neurohumoral aspects of renal function in 21 dogs. Five dogs were used as controls. Bipolar epicardial pacemaker leads were implanted at the apex of the right ventricle in 8 dogs and the dogs were subjected to ventricular pacing at 250-270 beats/min with an external pacemaker (Nihon Kohden) for a period of 11-21 days. This rapid pacing produced CHF. RF was induced by removal of the right kidney with ligation of the small branches of the left kidney in 8 dogs. Three dogs of each of the CHF and RF groups were used to produce CHF and RF in combination; one dog died due to infection. The glomerular filtration rates of the dogs with RF, CHF and CHF+RF were significantly lower than those of the controls, although among the dogs with $\mathrm{RF}, \mathrm{CHF}$ and $\mathrm{CHF}+\mathrm{RF}$, there were no significant differences. In spite of no differences in blood pressure and renal hemodynamics, the levels of plasma renin activity, norepinephrine and vasopressin of CHF+RF group were significantly higher than those of RF and CHF groups. Taken together, these data suggest that in patients with CHF compromised by RF neurohumoral factors are maximally activated.
\end{abstract}

Keywords: Atrial natriuretic peptide; Congestive heart failure; Chronic renal failure

\section{Introduction}

The heart and the kidneys act in tandem to regulate blood pressure, vascular tone, diuresis and maintain intravascular volume homeostasis and peripheral tissue perfusion [1-4]. Besides, the kidneys have a neuroendocrine function with interdependent physiological actions regulated by the Renin-Angiotensin-Aldosterone (RAA) system, Sympathetic Nervous System (SNS), vasopressin (AVP) and Atrial Natriuretic Peptide (ANP). Recently, Ronco et al. [5] emphasize the bidirectional nature of the heart-kidney interaction and the vast interrelated derangements that can take place in cardiorenal syndrome and hence, proposed that the recent definition of cardiorenal syndrome be modified into categories whose labels reflect the likely primary and secondary pathology and time frame. In clinical practice, patients with Congestive Heart Failure (CHF) compromised with Renal Dysfunction (RF) are found frequently [6]. In addition, for predicting adverse outcomes in CHF, worsening of kidney function is more important than the baseline kidney function [7]. Retrospective analysis of several large scale studies examining prognosis of CHF revealed that the magnitude of RF was an important determinant of survival [8]. According to classification of Ronco et al. [5], the presence of combined cardiac and RF is cardiorenal syndrome. A number of factors contribute to the pathogenesis of this type of cardiorenal syndrome; however, its pathophysiological process still remains under investigation. Among various factors, neurohumoral factors have been considered to be the most important factors for development of this type cardiorenal syndrome $[3,4]$.

In the present study, a canine model with CHF combined with RF was used to characterize the neurohumoral factors that play a role in the development of cardiorenal syndrome.

\section{Methods}

\section{Surgical preparation}

Twenty one male mongrel dogs weighing between 14 and $18 \mathrm{~kg}$ were used. All surgical procedures were performed aseptically under general anesthesia induced by pentobarbital sodium and maintained with halothane. Catheters (Tygon; US Stoneware, Akron, $\mathrm{OH}$ ) were placed in the right internal iliac artery and vein. Electromagnetic flow probes (model FD; Nihon Kohden Institute, Tokyo, Japan) were implanted around the ascending aorta in all dogs for evaluation of the changes in cardiac output, as described previously [9-13]. All catheters, leads and probes were inserted subcutaneously, externalized through the back between the scapulae and secured. Upon completion of surgery, the dogs were placed in individual cages to allow free mobility.

\section{Induction of congestive heart failure}

Bipolar epicardial pacemaker leads (Yuhuseiki Institute, Tokyo, Japan) were implanted at the apex of the right ventricle. The dogs were subjected to ventricular pacing at 250-270 beats/min with an external pacemaker (Nihon Kohden) for a period of 11-21 days.

*Corresponding author: Hiromichi Suzuki, MD, PhD, Department of Nephrology, Saitama Medical University, 38 Morohonngo, Moroyamamachi, Iruma gun, Saitama, 350-0495, Japan, Tel: 81-492-76-1620; Fax: +81-492-76-1620; E-mail iromichi@saitama-med.ac.jp

Received August 16, 2012; Accepted September 27, 2012; Published October 01,2012

Citation: Suzuki H, Matsumoto A, Murakami M, Naitoh M, Saruta T (2012) Canine Model of Cardiorenal Failure. J Nephrol Therapeut 2:127. doi:10.4172/21610959.1000127

Copyright: $\odot 2012$ Suzuki H, et al. This is an open-access article distributed under the terms of the Creative Commons Attribution License, which permits unrestricted use, distribution, and reproduction in any medium, provided the original author and source are credited. 


\section{Induction of renal failure}

The peritoneum overlying the right kidney was incised along the greater curvature. The renal artery, renal vein and ureter were isolated, triple ligated and transacted and the right kidney was removed. The peritoneum overlying the left kidney was incised along the greater curvature and the renal artery and interlobar branches were isolated such that the smallest branches were ligated [14].

\section{Production of congestive heart failure and renal failure in combination}

Three dogs of each CHF group and RF group were used to induce CHF and RF simultaneously; one dog died due to infection.

\section{Recovery after surgery}

During the recovery period and subsequent experiments, all animals were fed a diet containing $70 \mathrm{mmol}$ sodium and $60 \mathrm{mmol}$ potassium (Oriental Yeast, Tokyo, Japan) daily. The water content of the food was $7.9 \%$. Free access to tap water was permitted at all times. The dogs were placed on a regimen of antibiotics (aminobenzylpenicillin, 500 mg i.v. twice a day) for the first week and if the dogs failed to take in sufficient food or water, saline solution or $10 \%$ dextrose solution was administered intravenously. Following a training period of 2-3 weeks after the operation, all studies were carried out on the dogs during the sating stage from $8 \mathrm{AM}$ to $3 \mathrm{PM}$ in a quiet room. All procedures were conducted in accordance with institutional animal care guidelines.

\section{Monitoring procedures}

The arterial catheter was connected to a pressure transducer (model TP-400T; Nihon Kohden) for measurement of the arterial blood pressure and heart rate. The cardiac output was measured with a monitor (model MFV-3200; Nihon Kohden). The data for the Mean Arterial Pressure (MAP), heart rate and cardiac output were recorded with the dogs lying down and resting and were analyzed on a Macintosh computer, using an analog-to-digital converter made by the Macintosh Laboratory System (MacLab, Analog Digital Instruments, Castle Hill, New South Wales, Australia), at a sample rate of 20 points as described previously [10].

\section{Urine collection and administration of p-aminohippurate and inulin}

To investigate the renal function including the Urine Flow Rate (UFR), urinary sodium Cardiorenal Failure and potassium excretion (UnaV and $\mathrm{UkV}$, respectively), p-aminohippurate (PAH) clearance, inulinclearance and free water clearance $\left(\mathrm{cH}_{2} \mathrm{O}\right), 7$-Frballooncatheters (Create Medic, Yokohama, Japan) were temporarily inserted into the bladder of the dogs via the urethra and urine was collected. At $60 \mathrm{~min}$ before the start of control measurements, a bolus injection of 20\% PAH (200 mg) and 25\% inulin (1200 mg) was given, which was followed by continuous infusion of PAH $(3 \mathrm{mg} / \mathrm{min})$ and inulin $(12 \mathrm{mg} / \mathrm{min})$ to attain stable blood levels of PAH and inulin.

\section{Measurements of vasoactive substances}

Plasma Rennin Activity (PRA) was determined by Radioimmunoassay (RIA) using kits from Dinabott Raioiostope Inst., Tokyo, Japan. The intra-and inter assay Coefficients of Variation (CV) were 5.5-6.9\% and 3.7-8.2\%, respectively. Aldosterone (A) was estimated by RIA using kits from Daiichi Radioisotope Lab. Ltd., Tokyo, Japan. Norepinephrine (NE) and Epinephrine (E) were determined by the High-Performance Liquid Chromatography (HPLC)-trihydroxyindole method. PAH and inulin were measured with a colorimeter (model 7010; Hitachi, Tokyo, Japan). Serum and urinary electrolytes were estimated with a flame photometer (model 736; Hitachi). The AVP concentration was measured by radioimmunoassay employing a kit from MitsubishiYuka Bio-Chemical Laboratories (Tokyo, Japan) after Sep-Pak C18 extraction of plasma. The intra- and interassay coefficients of variation were $8.3-10.3 \%$ and $7.8-10.8 \%$, respectively. ANP was measured by radioimmunoassay employing kits from Eiken Chemical (Tokyo, Japan).

\section{Statistical analysis}

All data were expressed as the mean \pm Standard Error of Mean (SEM). Comparison among the groups was carried out using oneway analysis of variance followed by Neuman-Keuls test. Statistical significance was set at $\mathrm{p}<0.05$. The statistics were performed using the SAS program (SAS Institute, Cary, NC, USA).

\section{Results}

\section{Changes in hemodynamics}

The mean blood pressures of the control, $\mathrm{CHF}, \mathrm{RF}$ and $\mathrm{CHF}+\mathrm{RF}$ groups are shown in figure 1A. The mean blood pressures were $82 \pm 4$ $\mathrm{mmHg}$ in the control, $90 \pm 6$ in RF, $55 \pm 3$ in CHF and $66 \pm 4$ in CHF+RF groups. There was no statistically significant difference between the control and the dogs with RF; however, the blood pressures of the dogs with $\mathrm{CHF}$ and $\mathrm{CHF}+\mathrm{RF}$ were significantly lower than the control and $\mathrm{RF}$ groups. The mean cardiac output was $3.1 \pm 0.4 \mathrm{~L} / \mathrm{min}$ in the control, $3.0 \pm 0.4 \mathrm{~L} / \mathrm{min}$ in $\mathrm{RF}, 1.4 \pm 0.5 \mathrm{~L} / \mathrm{min}$ in $\mathrm{CHF}$ and $1.2 \pm 0.4 \mathrm{~L} / \mathrm{min}$ in $\mathrm{CHF}+\mathrm{RF}$ groups (Figure 1B). There were no significant differences between the control and the dogs with RF. However, the mean cardiac output of the dogs with $\mathrm{CHF}$ and dogs with $\mathrm{CHF}+\mathrm{RF}$ was lower than that of the control and RF groups.

\section{Changes in renal function}

Hourly urine output is shown in figure $2 \mathrm{~A}$. The volume of hourly urinary excretion was $29.9 \pm 5.1 \mathrm{ml} / \mathrm{hr}$ in the control, $24.0 \pm 4.0 \mathrm{in}$ $\mathrm{RF}, 15.1 \pm 2.9$ in $\mathrm{CHF}$ and $13.1 \pm 3.0$ in $\mathrm{CHF}+\mathrm{RF}$ groups. There were no significant differences between the control and the RF groups; however, the volume of hourly urine output of the dogs with CHF and $\mathrm{CHF}+\mathrm{RF}$ was lower than those of the control and RF groups. Similarly, urinary excretion of sodium was significantly lower in the dogs with $\mathrm{CHF}$ and $\mathrm{CHF}+\mathrm{RF}$ than the control and RF groups (Figure $2 \mathrm{~B}$ ). The glomerular filtration rate of the dogs with $\mathrm{RF}, \mathrm{CHF}$ and $\mathrm{CHF}+\mathrm{RF}$ was significantly lower than those of the control (Figure $3 \mathrm{~A}$ ). There were no significant differences among the dogs with RF, CHF and CHF+RF. Similarly, there were significant differences between the control and
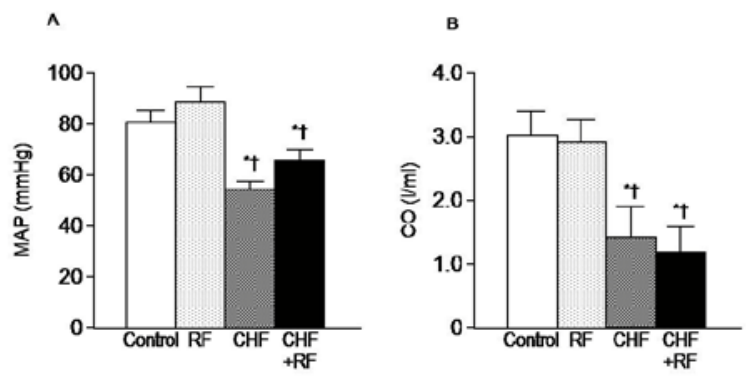

Figure 1: Mean blood pressure (MAP) $(A)$ and cardiac output $(C O)(B)$ of control dogs and dogs with renal dysfunction (RF) congestive heart failure (CHF), and $\mathrm{CHF}$ and $\mathrm{RF}$ in combination. ${ }^{*} \mathrm{P}<0.05$ vs. control, $+\mathrm{P}<0.05$ vs. RF. There were 5 dogs in each group. Abbreviations used in the following figures are the same as in the Figure 1. 

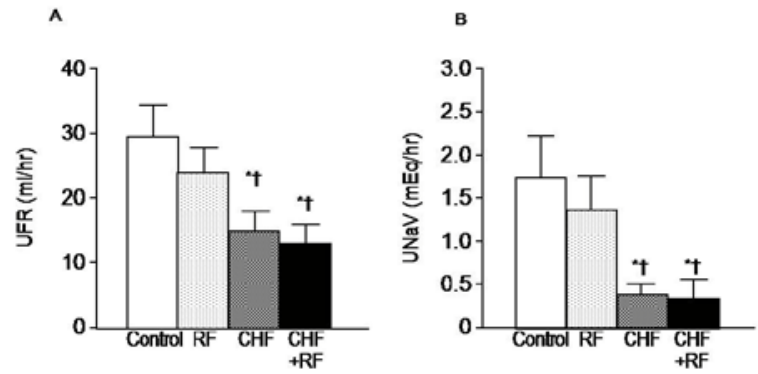

Figure 2: Urinary flow rate (UFR) (A) and urinary excretion of sodium (UNaV) (B) in control dogs, and dogs with RF, CHF, and CHF and RF in combination. ${ }^{*} \mathrm{P}<0.05$ vs. control, $+\mathrm{P}<0.05$ vs. RF. There were 5 dogs in each group.

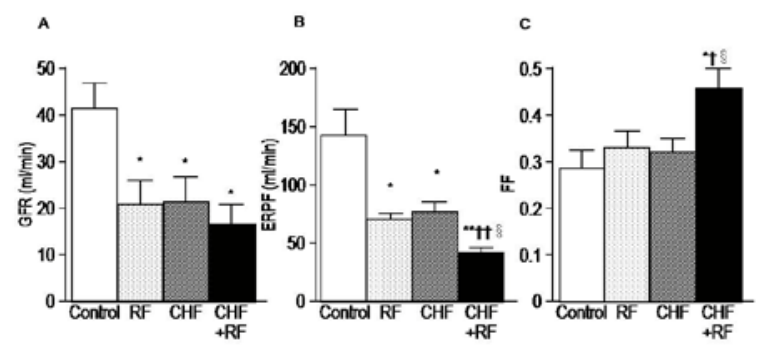

Figure 3: Glomerular filtration rate (GFR) (A), effective renal plasma flow (ERPF) (B) and filtration fraction (FF) (C), in control dogs and dogs with RF, $\mathrm{CHF}$, and $\mathrm{CHF}$ and $\mathrm{RF}$ in combination. ${ }^{*} \mathrm{P}<0.05$ vs. control, ${ }^{*} \mathrm{P}<0.01 \mathrm{vs}$. control, $+\mathrm{P}<0.05$ vs. $\mathrm{RF}$, and $\mathrm{P}<0.05$ vs. CHF. There were 5 dogs in each group.

the other 3 experimental groups in the levels of effective renal plasma flow (Figure $3 \mathrm{~B}$ ). Moreover, the levels of effective renal plasma flow of the dogs with $\mathrm{CHF}+\mathrm{RF}$ were significantly lower than those of RF and $\mathrm{CHF}$. The filtration fraction of the dogs with $\mathrm{CHF}+\mathrm{RF}$ was significantly greater than those of the control, RF and CHF (Figure 3C).

\section{Changes in humoral factors}

Changes in plasma renin activity and plasma aldosterone concentration: The mean PRA was $0.8 \pm 0.2 \mathrm{ng} / \mathrm{ml} / \mathrm{hr}$ in the control, $1.2 \pm 0.4 \mathrm{ng} / \mathrm{ml} / \mathrm{hr}$ in RF, $2.6 \pm 0.4 \mathrm{ng} / \mathrm{ml} / \mathrm{hr}$ in $\mathrm{CHF}$ and $4.4 \pm 0.7 \mathrm{ng} /$ $\mathrm{ml} / \mathrm{hr}$ in CHF+RF groups (Figure $4 \mathrm{~A}$ ). The mean PRA of the RF and CHF groups was significantly higher than that of the control group. Besides, the PRA of $\mathrm{CHF}+\mathrm{RF}$ group were significantly higher than those of RF and CHF groups. The concentration of plasma A was 76 $\pm 6 \mathrm{pg} / \mathrm{ml}, 93 \pm 14$ in RF, $393 \pm 55$ in CHF and $577 \pm 138$ in CHF+RF groups. There were no significant differences between the control and $\mathrm{RF}$ groups; however, the concentration of $\mathrm{PAC}$ in $\mathrm{CHF}$ and $\mathrm{CHF}+\mathrm{RF}$ groups was significantly higher than those of the control and RF groups (Figure 4B).

Changes in plasma norepinephrine and epinephrine: The plasma concentration of NE was $98 \pm 14 \mathrm{pg} / \mathrm{ml}$ in the control, $277 \pm 51 \mathrm{in} \mathrm{RF}$, $557 \pm 65$ in CHF and $705 \pm 118$ in CHF+RF (Figure 4A). The mean plasma concentration of NE in the RF group was significantly higher than that of the control group. The mean plasma concentration of $\mathrm{NE}$ in $\mathrm{CHF}+\mathrm{RF}$ groups was significantly higher than that of either $\mathrm{CHF}$ or RF groups. The plasma concentration of epinephrine (E) was $43 \pm$ $7 \mathrm{pg} / \mathrm{ml}$ in the control, $66 \pm 13 \mathrm{in} \mathrm{RF}, 242 \pm 65$ in CHF and $261 \pm$ 88 in CHF+RF groups and was not significantly different between the control and RF groups. However, the plasma concentration of $\mathrm{E}$ was significantly higher in the $\mathrm{CHF}$ and $\mathrm{CHF}+\mathrm{RF}$ groups than those of the control and RF groups (Figure 4B).
Changes in plasma atrial natriuretic peptide and plasma arginine vasopressin: The plasma concentration of ANP was $41 \pm 3 \mathrm{pg} / \mathrm{ml}$ in the control, $43 \pm 6$ in RF, and $323 \pm 62$ in CHF and $383 \pm 74$ in CHF+RF groups (Figure $5 \mathrm{~A}, 5 \mathrm{~B}$ ). The concentration of ANP in the RF group was significantly higher than that of the control group. The concentration of ANP in the CHF and CHF+RF groups was significantly higher than that of the RF group. The plasma concentration of AVP was $1.3 \pm 0.5$ $\mathrm{pg} / \mathrm{ml}$ in the control group, $1.2 \pm 0.5$ in RF, $3.9 \pm 0.5$ in CHF and 7.6 \pm 1.8 in $\mathrm{CHF}+\mathrm{RF}$ groups. The concentration of $\mathrm{AVP}$ in $\mathrm{CHF}+\mathrm{RF}$ was significantly higher than those in the control, RF and CHF groups (Figure 6A, 6B).

\section{Discussion}

In the present study, dogs with $\mathrm{CHF}+\mathrm{RF}$ showed that 1) the RAA system was activated, 2) the SNS was enhanced and 3) the levels of
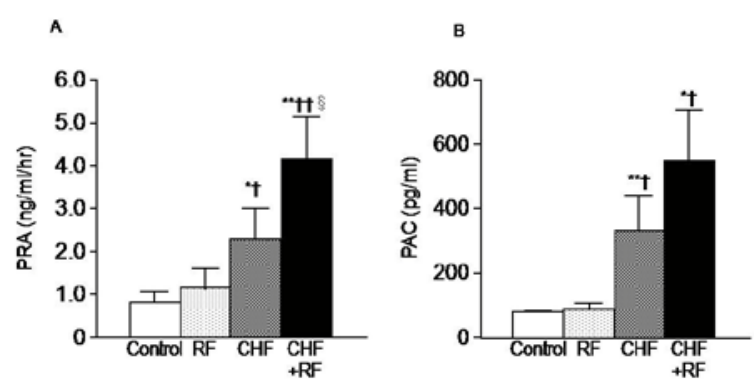

Figure 4: Plasma renin activity (PRA) (A) and plasma aldosterone concentration (PA) (B) in control dogs, and dogs with RF, CHF and $\mathrm{CHF}$ and $\mathrm{RF}$ in combination. ${ }^{*} \mathrm{P}<0.05$ vs. control, ${ }^{* *} \mathrm{P}<0.01$ vs. control, $+\mathrm{P}<0.05$ vs. $R F$, $++\mathrm{P}<0.01$ vs. $R F$, and $\mathrm{P}<0.05$ vs. CHF. There were 5 dogs in each group.
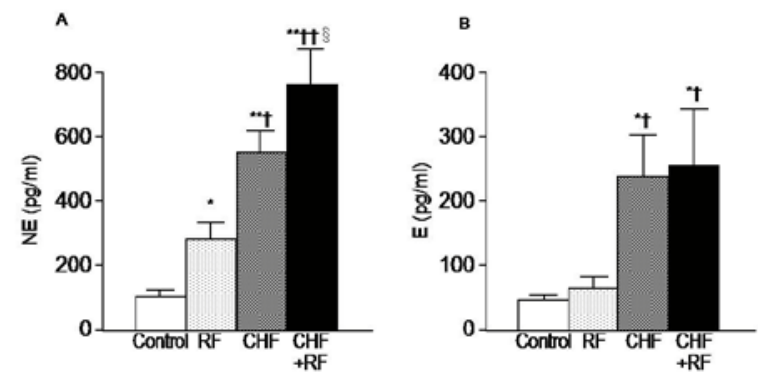

Figure 5: Concentration of plasma norepinephrine (NE) (A) and epinephrine (E) (B) in control dogs, and dogs with RF CHF, and CHF and RF in combination, ${ }^{*} \mathrm{P}<0.05$ vs. control, ${ }^{*} \mathrm{P}<0.01$ vs. control, $+P<0.05$ vs. $R F,++P<0.01$ vs. RF. $\mathrm{P}<0.05$ vs. CHF. There were 5 dogs in each group.
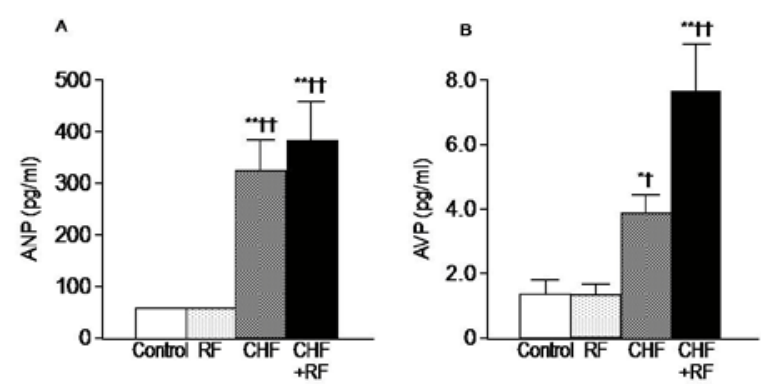

Figure 6: Concentration of plasma atrial natriuretic peptide (ANP) (A) and plasma vasopressin (AVP) (B) in control dogs, and dogs with RF, CHF and $\mathrm{CHF}$ and $\mathrm{RF}$ in combination. ${ }^{*} \mathrm{P}<0.05$ vs. control, ${ }^{* *} \mathrm{P}<0.01$ vs. control, $+P<0.05$ vs. RF, $++P<0.01$ vs. CHF $+R F$. There were 5 dogs in each group. 
AVP was elevated compared with dogs with CHF or RF alone. These 3 major neurohumoral repressor mechanisms are known to be involved in pathophysiological processes in patients with CHF. Compared with these dramatic changes of dogs with CHF, dogs with RF did not show significant changes in neurohumoral systems. In dogs with RF, both renal plasma flow and glomerular filtration rate were significantly reduced compared with those of the controls, indicating that these dogs had a mild RF.

In dogs with $\mathrm{CHF}$ and $\mathrm{RF}$, reduction of effective renal plasma flow was accompanied by a marked increase in PRA that produced abundant angiotensin II. This increase in angiotensin II constricted the efferent arteriole of the glomerulus and induced higher filtration fraction compared with those of the dogs with CHF. Moreover, these data suggest that maximally activated neurohumoral factors play a crucial role in the pathophysiological process in animals and humans with both CHF and RF.

Although the role of vasopressin in CHF has been investigated, it still remains unclear. In humans with $\mathrm{CHF}$, the AVP values are variable. Johnston et al. [15] reported that the AVP levels were significantly elevated, whereas other studies reported that it was not. In our previous study, dogs with CHF exhibited modest but significant increases in AVP level. In addition, Naitoh et al. [10] clearly demonstrated using both vasopressin type 1 (V1) receptor and type 2 (V2) receptor blockers that AVP plays a significant role in increasing the vascular tone through the V1 receptor and plays a major role in retaining free water through the $\mathrm{V} 2$ receptor. In dogs with $\mathrm{CHF}$ and $\mathrm{RF}$, the values of AVP tended to be higher significantly than those in dogs with CHF, suggesting that the role of AVP in cardiorenal function might be more potent than in dogs with CHF. However, because a special role for AVP was reported in patients and experimental animals with RF [16-18], further investigations using V1 and V2 antagonists are needed to clarify the role of AVP in cardiorenal syndrome. The sympathetic nervous system is initially activated in CHF by the baroreflex sensors to provide inotropic support and preserve cardiac output. In dogs with RF, slight but significant elevation in NE was found and this is in agreement with the previous reports in which the SNS was activated in RF [19-21]. Whereas, in dogs with a combination of RF and CHF, elevations in $\mathrm{NE}$ were higher than those with CHF alone, showing that in $\mathrm{CHF}$ and $\mathrm{RF}$, the SNS is maximally activated. The exact underlying pathogenesis of cardiorenal syndrome is unclear; however, interconnections of the RAA, the SNS and AVP systems are possibly involved in a complex manner. In addition to these syndromes, the balance between Nitric Oxide (NO) and Radical Oxygen Species (ROS) was shown to shift towards the latter by increased production of ROS, a low antioxidant status and lower availability of NO. These processes connecting with the production of proinflammatory cytokines, might contribute to the formation of cardiorenal syndrome [22]. In conclusion, our canine model with a combination of $\mathrm{CHF}$ and RF provides a useful tool for investigating mechanisms of cardiorenal syndrome as well as for research and development of drugs for treatment of patients with cardiorenal syndrome.

\section{References}

1. Shlipak MG, Massie BM (2004) The Clinical Challenge of Cardiorenal Syndrome. Circulation 110: 1514-1517.

2. Amann K, Wanner C, Ritz E (2006) Cross-talk between the kidney and the cardiovascular system. J Am Soc Nephrol 17: 2112-2119.
3. Pokhrel N, Maharjan N, Dhakal B, Arora RR (2008) Cardiorenal syndrome: A literature review. Exp Clin Cardiol 13: 165-170.

4. Mahapatra HS, Lalmalsawma R, Singh NP, Kumar M, Tiwari SC (2009) Cardiorenal syndrome. Iran J Kidney Dis 3: 61-70.

5. Ronco C, Haapio M, House AA, Anavekar N, Bellomo R (2008) Cardiorenal Syndrome. J Am Coll Cardiol. 52: 1527-1539.

6. Shlipak MG, Katz R, Sarnak MJ, Fried LF, Newman AB, et al. (2006) Cystatin $\mathrm{C}$ and prognosis for cardiovascular and kidney outcomes in elderly persons without chronic kidney disease. Ann Intern Med 145: 237-246.

7. laina A, Silverberg DS, Wexler D (2005) Therapy insight: congestive heart failure, chronic kidney disease and anemia, the cardio-renal-anemia syndrome. Nat Clin Pract Cardiovasc Med 2: 95-100.

8. Silverberg D, Wexler D, Blum M, Schwartz D, laina A (2004) The association between congestive heart failure and chronic renal disease. Curr Opin Nephrol Hypertens 13: 163-170.

9. Naitoh M, Suzuki H, Arakawa K, Matsumoto A, Ichihara A, et al. (1997) Role of kinin and renal ANG II blockade in acute effects of ACE inhibitors in low-renin hypertension. Am J Physiol 272: H679-H687.

10. Naitoh M, Suzuki H, Murakami M, Matsumoto A, Arakawa K, et al. (1994) Effects of oral AVP receptor antagonists OPC-21268 and OPC-31260 on congestive heart failure in conscious dogs. Am J Physiol. 267: H2245-H2254.

11. Naitoh M, Suzuki H, Murakami M, Matsumoto A, Ichihara A, et al. (1993) Arginine vasopressin produces renal vasodilation via $V 2$ receptors in conscious dogs. Am J Physiol 265:R934-R942.

12. Arakawa K, Suzuki H, Naitoh M, Matsumoto A, Hayashi K, et al. (1996) Role of adenosine in the renal responses to contrast medium. Kidney Int 49: 11991206.

13. Murakami M, Suzuki H, Naitoh M, Matsumoto A, Kageyama Y, et al. (1995) Blockade of the renin-angiotensin system in heart failure in conscious dogs. $J$ Hypertens 13: 1405-1412.

14. Brassard JA, Meyers KM, Person M, Dhein CR (1994) Experimentally induced renal failure in the dog as an animal model of uremic bleeding. J Lab Clin Med 124: 48-54.

15. Johnston Cl, McGrath BP, Phillip P, Abraham JM, Hodsman GP (1988) Vasopressin: cellular and integrative functions. In: Cowley JA, Liard JF, Ausiello D (eds.). Vasopression in Congestive Heart Failure: Clinical and Experimental Studies. Raven, New York.

16. Bankir L, Bouby N (1991) Vasopressin and urinary concentration: additional risk factors in the progression of chronic renal failure. Am J Kidney Dis 17: 20-26.

17. Okada H, Suzuki H, Kanno Y, Saruta T (1996) Evidence for the involvement of vasopressin in the pathophysiology of adriamycin-induced nephropathy in rats. Nephron 72: 667-672.

18. Okada H, Suzuki H, Kanno Y, Yamamura $Y$, Saruta $T$ (1994) Effects of vasopressin $\mathrm{V} 1$ and $\mathrm{V} 2$ receptor antagonists on progressive renal failure in rats. Clin Sci (Lond) 86: 399-404.

19. Masuo K, Lambert GW, Esler MD, Rakugi H, Ogihara T, et al. (2010) The role of sympathetic nervous activity in renal injury and end-stage renal disease. Hypertens Res 33: 521-528.

20. Penne EL, Neumann J, Klein IH, Oey PL, Bots ML, et al. (2009) Sympathetic hyperactivity and clinical outcome in chronic kidney disease patients during standard treatment. J Nephrol 22: 208-215.

21. Neumann J, Ligtenberg G, Klein II, Koomans HA, Blankestijn PJ (2004) Sympathetic hyperactivity in chronic kidney disease: pathogenesis, clinical relevance, and treatment. Kidney Int 65: 1568-1576.

22. Tetta C, Biasioli S, Schiavon R, Inguaggiato P, David S, et al. (1999) An overview of haemodialysis and oxidant stress. Blood Purif 17: 118-126. 